\title{
Study on the Electrochemical Oxidation Treatment of Coking Wastewater by DSA Anode
}

\author{
Qiyuan Gu, Jin Zheng \\ School of Civil and Environmental Engineering \\ University of Science and Technology \\ Beijing, Beijing 100083, China \\ e-mail: guqiyuan1984@139.com
}

\begin{abstract}
Commercial DSA anode was employed for electrochemical oxidation treatment of coking wastewater, and the effect of electrolytes, working potential, and ultraviolet irradiation were examined. An effective removal of chemical oxygen demand (COD), thiocyanate $\left(\mathrm{SCN}^{-}\right)$, volatile phenol and total nitrogen ( $\mathrm{TN}$ ) was observed during electrochemical oxidation process. The presence of $\mathrm{NaCl}$ $(0.01 \mathrm{~mol} / \mathrm{L})$ enhanced the TN removal significantly, and the removal of TN under $9 \mathrm{~V}$ working potential improved from $15.9 \%$ in the absence of $\mathrm{NaCl}$ to $56.4 \%$ in the presence, which can be ascribed to the indirect oxidation of hypochlorite. Both the working potential and ultraviolet irradiation were capable of enhancing the degradation efficiency. From the UV-Vis absorbance curves before and after the electrochemical oxidation, the pollutants in the coking wastewater were efficiently removed and this indicates that electrochemical oxidation is a practical approach for the coking wastewater treatment.
\end{abstract}

Keywords-DSA; Coking wastewater; Electrochemical oxidation; Wastewater treatment .

\section{INTRODUCTION}

Recently, advanced oxidation technology accompanied by the generation of hydroxyl radicals for organic wastewater treatment has attracted a great deal of attention because of effective removal of organic and inorganic pollutants [1-3]. Electrochemical oxidation has attracted wide attention as one of the environmentalfriendly technologies in wastewater treatment processes. Other advantages of electrochemical oxidation include high efficiency in organic degradation, simple structure and easy control [4,5]. Electrochemical oxidations of various refractory pollutants have been extensively studied, such as dyes, phenol, and aniline [6].

Coking wastewater is generated in the process of coal chemical production. The chemical composition of coal process wastewater is very complex and contains a large number of toxic compounds such as phenols, thiocyanate and ammonia. Phenols are highly toxic compounds even at low concentrations and the discharge of the wastewater containing phenols is restricted severely. High concentration of thiocyanate is toxic to aquatic species and vertebrates. Moreover, ammonia is also toxic to aquatic organisms, especially the higher forms, such as fish, even at low concentrations of $0.5 \mathrm{mg} / \mathrm{L}$ [7]. Removal of organic and inorganic pollutants from the coking wastewater is a complicated process and all contaminants must be treated effectively.

Conventional treatment of coking wastewater includes solvent extraction of phenolic compounds, steam stripping of ammonia and biological treatment. Activated sludge process is a prevalent biological process treating coking wastewater, which is unsatisfactory to meet the discharge standard because of the presence of toxic and inhibitory compounds and the influent shock load. Although new biological reactor and process have been developed, such as the sequencing batch reactor (SBR), the anaerobicanoxic-oxic process [8-10], these processes always cannot achieve high degradation efficiency because the shock load is beyond the designed capacity.

Researchers have made some study on electrochemical oxidation treating real coking wastewater [11]. Electrochemical oxidation is always chosen as advanced treatment for bio-chemical treatment effluent, and to degrade the residual ammonia nitrogen and mineralize a variety of bio-refractory pollutants. Although electrochemical oxidation process has been successfully employed for the removal of toxic compounds as posttreatment, there is less information on removal coking wastewater as pretreatment to resist the shock load.

This paper presented the feasibility of DSA anode system as a pretreatment of coking wastewater. Electrolysis of coking wastewater was carried out under different supporting electrolytes, working voltages, initial solution $\mathrm{pH}$ and ultraviolet irradiation, with the goal of optimizing the electrochemical oxidation process using DSA anode and accumulating data for the design of a full scale process.

\section{MATERIALS AND METHODS}

\section{A. Coking wastewater}

The coking wastewater was obtained from a coke process plant in He Nan. The chemical oxygen demand (COD) was $4296.4 \mathrm{mg} / \mathrm{L}$, total nitrogen (TN) $308.3 \mathrm{mg} / \mathrm{L}$, thiocyanate $\left(\mathrm{SCN}^{-}\right) \quad 852.2 \mathrm{mg} / \mathrm{L}$, volatile phenol 876.6 $\mathrm{mg} / \mathrm{L}$. The wastewater was diluted 10 times before used; The $\mathrm{pH}$ of the wastewater was adjusted to the value of 9.0 with $0.1 \mathrm{M} \mathrm{NaOH}$ and $\mathrm{HCl}$ solutions. All the regents used were of analytical grade. 


\section{B. Experimental method}

The DSA electrode was commercial $\mathrm{Ti} / \mathrm{Ru}_{0.3} \mathrm{Ti}_{0.7} \mathrm{O}_{2}$ electrode, DSA anode and $\mathrm{Ti}$ cathode, the distance between the two electrode plates was $10 \mathrm{~mm}$. Every test dose was to put $400 \mathrm{ml}$ coking wastewater into $500 \mathrm{ml}$ beaker, and magnetic stirrer was used to stir the solution for electrochemical degradation. The degradation time needed $6 \mathrm{~h}$. The concentration of electrolyte $\mathrm{Na}_{2} \mathrm{SO}_{4}$ and $\mathrm{NaCl}$ are all $0.01 \mathrm{~mol} / \mathrm{L}$. $0.1 \mathrm{M} \mathrm{H}_{2} \mathrm{SO}_{4}$ and $\mathrm{NaOH}$ were used to adjust $\mathrm{pH}$ Value of solution. Constant voltage was provided by DH1715A-3 bistable regulated current supply (Bei Jing Da Hua wireless Instrument).

The commercial DSA electrode $\left(\mathrm{Ti} / \mathrm{Ru}_{0.3} \mathrm{Ti}_{0.7} \mathrm{O}_{2}\right)$ was used as anode, the titanium electrode was used as cathode, and the distance between the two electrode plates was 10 $\mathrm{mm}$. For each experiment, $400 \mathrm{ml}$ of the raw wastewater was put into a $500 \mathrm{ml}$ beaker, and the wastewater was stirred by a magnetic stirrer at $120 \mathrm{rpm}$ for $6 \mathrm{~h}$ at different working voltages. At the end of the experiment, water sample was collected from the beaker and was measured according to the following methods. $0.01 \mathrm{M} \mathrm{Na}_{2} \mathrm{SO}_{4}$ and $\mathrm{NaCl}$ solutions were used to keep the electric conductivity of the wastewater.

\section{Analysis method}

All the samples were analyzed immediately after filtered through $0.45-\mu \mathrm{m}$ filter paper. The soluble COD, volatile phenol, total nitrogen were measured in accordance with Standard Methods for Water and Wastewater Examination. Thiocyanate $\left(\mathrm{SCN}^{-}\right)$was measured by ferric colorimetric method. $\mathrm{pH}$ was measured by using $\mathrm{pH}$ meter (PHS-2C, Hanna instruments, Italia).

\section{RESULTS AND DISCUSSIONS}

\section{A. The influence of supporting electrolyte}

The real coking wastewater contains high amount of salts, which mainly consist of chloride and sulfates ions. The conductivity of the coking wastewater is $8430 \mu \mathrm{s} / \mathrm{cm}$, and that of $0.01 \mathrm{M} \mathrm{NaCl}$ solution is $1175 \mu \mathrm{s} / \mathrm{cm}$. The conductivity of $0.01 \mathrm{M} \mathrm{NaCl}$ solution is similar with the coking wastewater used in this experiment which was diluted with tap water. Electrolyte can be effective to increase current density and improve reaction rate of solution. So this experiment initially investigated the influence of different supporting electrolytes on the performance of electrochemical oxidation using DSA anode for treatment of coking wastewater. $0.01 \mathrm{M} \mathrm{NaCl}$ and $0.01 \mathrm{M} \mathrm{Na}_{2} \mathrm{SO}_{4}$ were added into the wastewater as electrolytes, respectively. Fig. 1 showed that COD removal rate of electrochemical oxidation coking wastewater without electrolyte was $18.8 \%$. The COD removal rate increased to $58.7 \%$ and $32.2 \%$ when $0.01 \mathrm{M}$ $\mathrm{NaCl}$ and $0.01 \mathrm{M} \mathrm{Na} \mathrm{SO}_{4}$ were used as supporting electrolyte, respectively. The results indicated the existence of electrolyte in coking wastewater is beneficial to improve degradation efficiency. The COD removal rate increased to $26.5 \%$ when $\mathrm{NaCl}$ was used as supporting electrolyte instead of $\mathrm{Na}_{2} \mathrm{SO}_{4}$. The evolution tendencies of removal rate of volatile phenol, $\mathrm{SCN}^{-}$and total Nitrogen in supporting media containing $0.01 \mathrm{M} \mathrm{NaCl}$ and $0.01 \mathrm{M}$ $\mathrm{Na}_{2} \mathrm{SO}_{4}$ were similar. The main reason is that electrolyte enhanced prominently the current density, accelerated electron transfer between anode and contaminations. Degradation efficiency was improved. The degradation of contaminations could be direct oxidation and indirect oxidation. In the present of $\mathrm{Cl}^{-}$and $\mathrm{SO}_{4}{ }^{2-}$, reactions (1), (2), (3) could take place on the anode.

$$
\begin{gathered}
2 \mathrm{Cl}^{-} \rightarrow \mathrm{Cl}_{2}+2 \mathrm{e}^{-} \\
\mathrm{Cl}_{2}+\mathrm{H}_{2} \mathrm{O} \rightarrow \mathrm{ClO}^{-}+\mathrm{H}^{+}+\mathrm{Cl}^{-} \\
2 \mathrm{Na}_{2} \mathrm{SO}_{4}+2 \mathrm{OH} \cdot \rightarrow \mathrm{Na}_{2} \mathrm{~S}_{2} \mathrm{O}_{8}+2 \mathrm{H}_{2} \mathrm{O}
\end{gathered}
$$
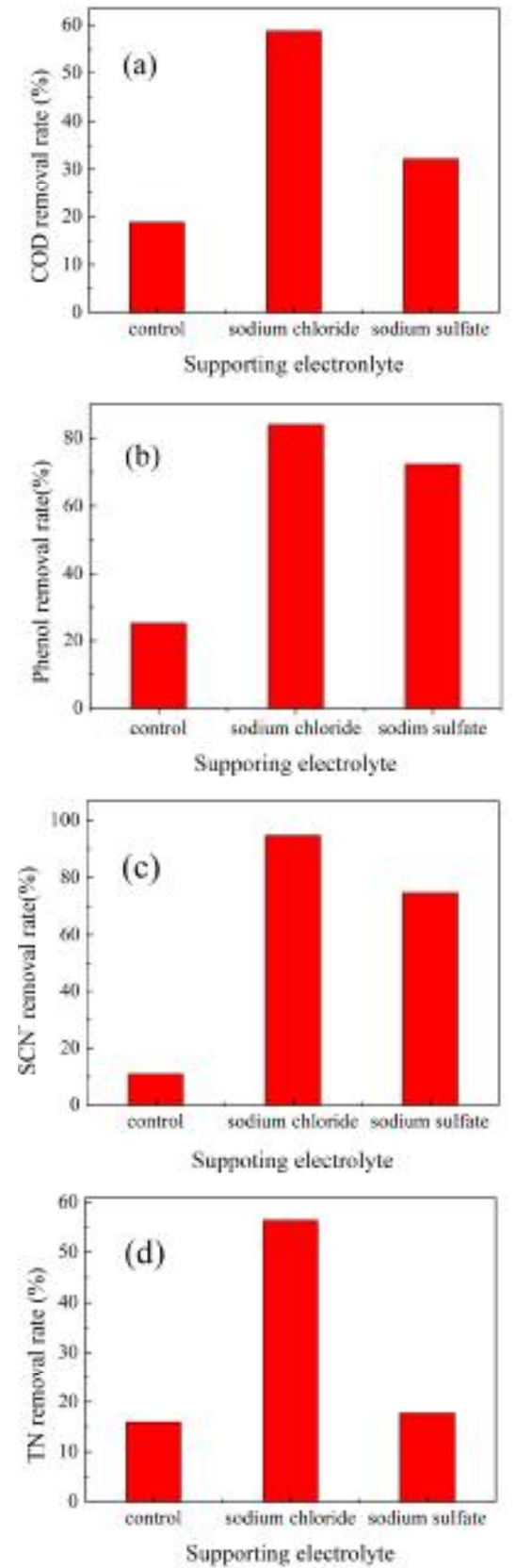

Fig.1: Removal efficiencies of $\mathrm{COD}(\mathrm{a})$, phenol(b), $\mathrm{SCN}^{-}(\mathrm{c})$, $\mathrm{TN}(\mathrm{d})$ by adding different support electrolytes.

In the electrochemical oxidation, hypochloric acid ( $\mathrm{HClO})$ was formed through oxidation of chloride, and reacted with the contaminations in the wastewater. However, the effect of indirect electrochemical oxidation of $\mathrm{S}_{2} \mathrm{O}_{8}{ }^{2-}$ is not obvious.

It is worthwhile to note that the $\mathrm{TN}$ removal rates in the presence of $\mathrm{NaCl}$ and $\mathrm{Na}_{2} \mathrm{SO}_{4}$ are different. The 
removal of $\mathrm{TN}$ under $9 \mathrm{~V}$ working potential improved from $15.9 \%$ in the absence of $\mathrm{NaCl}$ to $56.4 \%$ in the presence, while the removal of TN only improved from $15.9 \%$ in the absence of $\mathrm{Na}_{2} \mathrm{SO}_{4}$ to $17.7 \%$ in the presence. That can be ascribed to the indirect oxidation of hypochlorite. Hypochloric acid was formed through oxidation of chloride in the wastewater, and the ammonia nitrogen could be removed by indirect oxidation (Reaction $4,5,6)$.

$$
\begin{aligned}
\mathrm{NH}_{3}+\mathrm{HOCl} & \rightarrow \mathrm{NH}_{2} \mathrm{Cl}+\mathrm{H}_{2} \mathrm{O} \\
\mathrm{NH}_{2} \mathrm{Cl}+\mathrm{HOCl} & \rightarrow \mathrm{NHCl}_{2}+\mathrm{H}_{2} \mathrm{O} \\
\mathrm{NHCl}_{2}+\mathrm{HOCl} & \rightarrow \mathrm{NCl}_{3}+\mathrm{H}_{2} \mathrm{O}
\end{aligned}
$$

The generated chloramine mainly consists of monochloramine and dichloramine. With the constant forming of free chlorine, the content of chloramine is increasing. When all ammonia nitrogen was oxidized to chloramine, the reaction between hypochlorous acid and chloramine is as (7).

$$
4 \mathrm{NHCl}_{2}+3 \mathrm{HOCl} \rightarrow \mathrm{N}_{2}+\mathrm{N}_{2} \mathrm{O}+7 \mathrm{HCl}+2 \mathrm{H}_{2} \mathrm{O}
$$

The chemical reaction (7) makes to remove total Nitrogen in the used coking wastewater, which is also the reason that the removal of total nitrogen cannot obviously promoted in the present of $\mathrm{Na}_{2} \mathrm{SO}_{4}$. But the coking wastewater contains chloride ion, the added $\mathrm{Na}_{2} \mathrm{SO}_{4}$ improves the current density of electrodes so that evolved chlorine reaction was accelerated on the anode. However, the indirect electrochemical oxidation of $\mathrm{S}_{2} \mathrm{O}_{8}{ }^{2-}$ which is produced by $\mathrm{Na}_{2} \mathrm{SO}_{4}$ is not obvious and the function to improvement of denitrification rate was limited.

B. The influence of different working voltages.
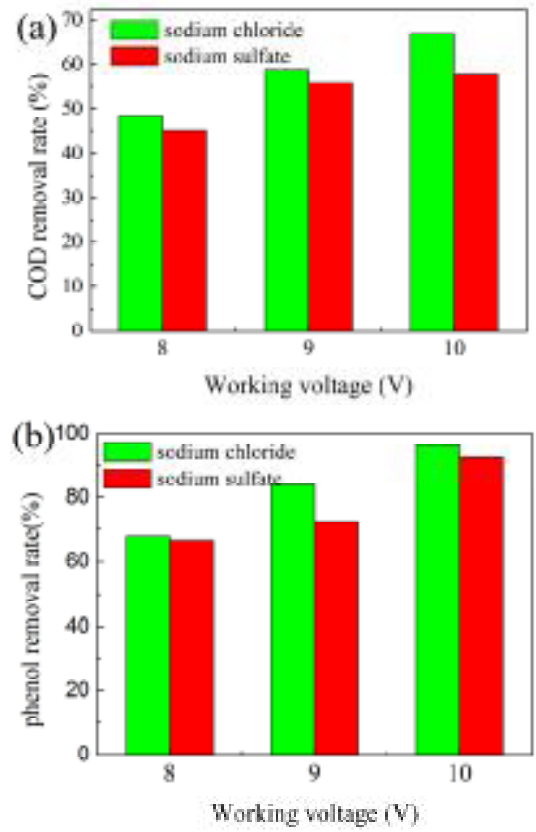
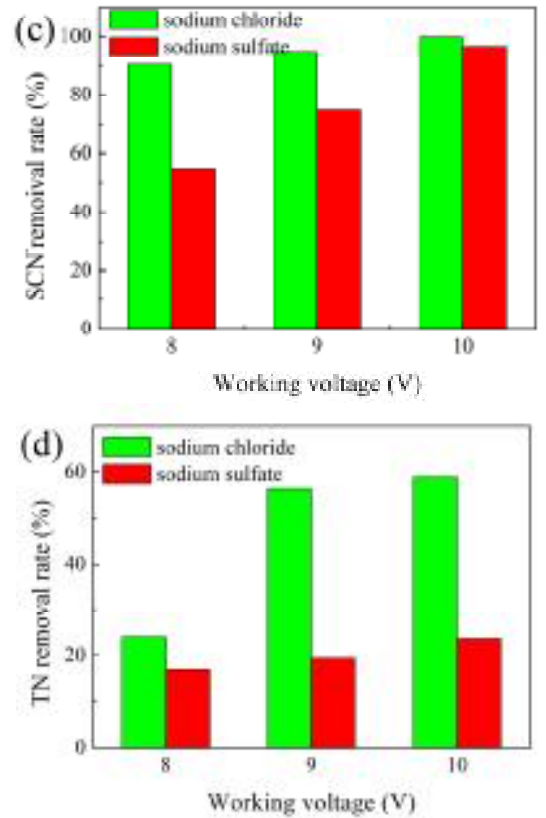

Fig.2: Removal efficiencies of $\mathrm{COD}(\mathrm{a})$, phenol(b), $\mathrm{SCN}^{-}(\mathrm{c})$, $\mathrm{TN}(\mathrm{d})$ under the electrolysis conditions of different working voltages.

Fig. 2 showed the evolution of removal rate of COD, $\mathrm{TN}$, phenols and $\mathrm{SCN}^{-}$as a function of electrochemical oxidation at different working voltages in the presence of $0.01 \mathrm{M} \mathrm{NaCl}$ and $0.01 \mathrm{M} \mathrm{Na}_{2} \mathrm{SO}_{4}$. Working voltage had a greater impact on the degradation efficiency of electrochemical oxidation. The results indicated that with the increase of working voltage from $8 \mathrm{~V}$ to $10 \mathrm{~V}$, the removal rate of $\mathrm{COD}$, volatile phenol, $\mathrm{SCN}^{-}$and total nitrogen were all improved stably. As for the removal rate of total nitrogen, the removal rate of $9 \mathrm{~V}$ and $10 \mathrm{~V}$ were $56.4 \%$ and $58.9 \%$ in the presence of $0.01 \mathrm{M} \mathrm{NaCl}$, which were improved significantly compared with $24 \%$ of removal rate at $8 \mathrm{~V}$. In the presence of $0.01 \mathrm{M} \mathrm{Na}_{2} \mathrm{SO}_{4}$, the $\mathrm{TN}$ removal rates of $8 \mathrm{~V}, 9 \mathrm{~V}$ and $10 \mathrm{~V}$ were $17.0 \%, 19.5 \%$ and $23.7 \%$ respectively. These indicated that the performance of $\mathrm{TN}$ removal rate cannot be improved significantly in the presence of supporting electrolyte $\mathrm{Na}_{2} \mathrm{SO}_{4}$, while the TN removal rate elevates effectively in the presence of supporting electrolyte $\mathrm{NaCl}$. 
C. The performance of ultraviolet radiation and the destruction of the chromophore for electrochemical oxidation

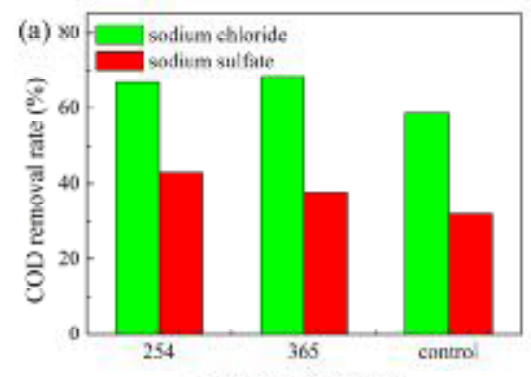

UV wavelength (nm)
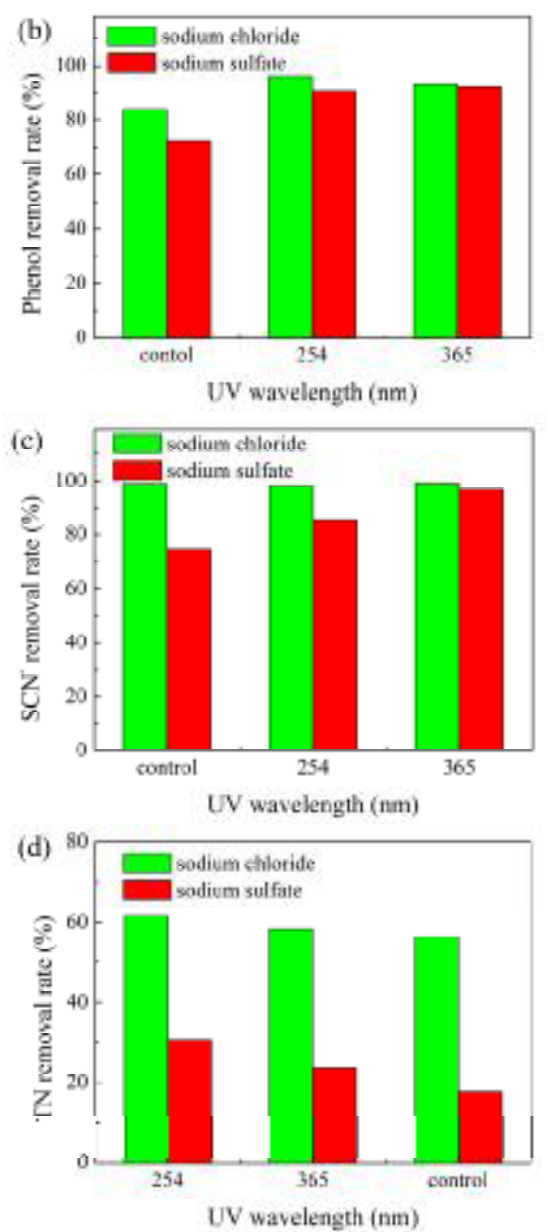

Fig.3: Removal efficiencies of $\operatorname{COD}(a)$, phenol(b), SCN-(c), $\mathrm{TN}(\mathrm{d})$ under ultraviolet irradiation with different UV wavelength.

Ultraviolet irradiation can degrade the contaminants in coking wastewater by direct photolysis oxidation and indirect oxidation which is accompanied by the generation of hydroxyl radicals. Additionally, ultraviolet irradiation can stimulate $\mathrm{TiO}_{2}, \mathrm{RuO}_{2}$ on the DSA anode to generate active species which contributed to the removal of COD, volatile phenol, $\mathrm{SCN}^{-}$and total Nitrogen such as active holes and hydroxyl radicals. Fig. 3 showed that in the presence of $\mathrm{Na}_{2} \mathrm{SO}_{4}$, the removal rates of electrochemical oxidation alone, $365 \mathrm{~nm}$ and $254 \mathrm{~nm}$ ultraviolet irradiation photoelectrochemical oxidation are $31.8 \%, 37.6 \%$ and $42.8 \%$, respectively. The results proved that ultraviolet radiation can effectively enhance COD oxidation efficiency.

Fig. 4 showed the UV-Vis absorption spectrogram of coking wastewater before and after treatment.it can be seen that there is a significant absorption peak at $269 \mathrm{~nm}$ in the spectrogram of wastewater before treatment. The absorption peak is corresponding to phenols organic pollutants. The peak was disappeared completely after the electrochemical oxidation treatment. Otherwise the peaks below $250 \mathrm{~nm}$ have also been significantly reduced. These indicated that organic pollutants have been degradation and mineralization to some extent, which accord with the results of COD degradation. So the electrochemical oxidation which generates the active species such as active holes and hydroxyl radicals can be employed for the simultaneous removal of COD, volatile phenol, $\mathrm{SCN}^{-}$ and total nitrogen, and the oxidation process has not selective.
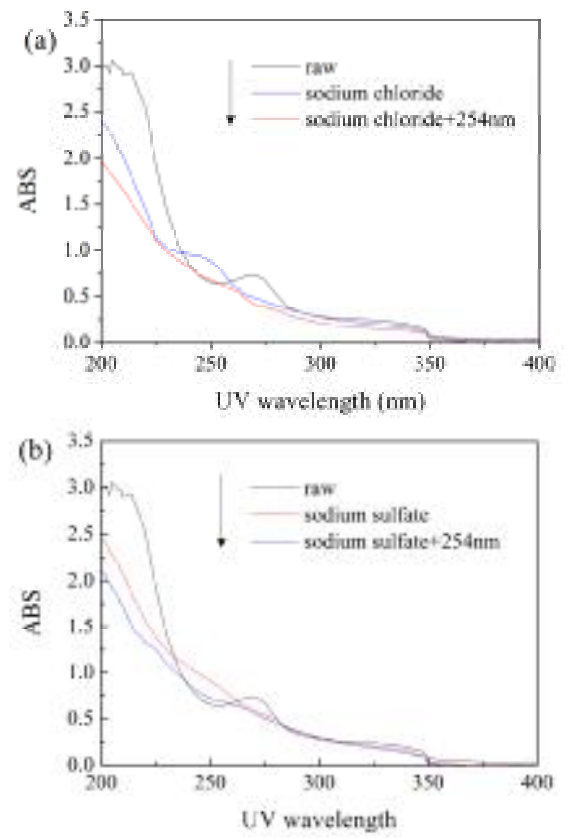

Fig.4: UV-Vis spectra of coking wastewater before and after $254 \mathrm{~nm}$ ultraviolet irradiation with different support electrolyte: sodium chloride (a) and sodium sulfate (b).

\section{CONCLUSIONS}

The electrochemical oxidation using DSA anode was very promising for coking wastewater treatment. The effect of electrolyte, work voltage, solution $\mathrm{pH}$ conditions and ultraviolet irradiation were investigated. The degradation efficiency of COD, volatile phenol, SCNand total nitrogen in the treated coking wastewater can be significantly enhanced in the presence of supporting electrolytes $\mathrm{NaCl}$ and $\mathrm{Na}_{2} \mathrm{SO}_{4}$. However, the TN removal rate cannot be improved obviously in the presence of $\mathrm{Na}_{2} \mathrm{SO}_{4}$, and the removal rate of the main contaminants in the coking wastewater in the presence of $\mathrm{NaCl}$ is much greater than that in the presence of $\mathrm{Na}_{2} \mathrm{SO}_{4}$. With the increasing of working voltage, the removal rates of COD, volatile phenol, SCN- and total nitrogen are all improved. In the different initial $\mathrm{pH}$ value solution, the removal rates of $\mathrm{COD}$, volatile phenol, $\mathrm{SCN}^{-}$and total nitrogen in the presence of $\mathrm{NaCl}$ are greater than that in the presence of $\mathrm{Na}_{2} \mathrm{SO}_{4}$. Ultraviolet radiation can be effective to enhance 
the degradation efficiency of coking wastewater, and be employed for the simultaneous removal of COD, volatile phenol, $\mathrm{SCN}^{-}$and total nitrogen. The UV-Vis absorption spectrum analysis proved the organic pollutants of coking wastewater has an obvious degradation in the photoelectrochemical oxidation process.

\section{ACKNOWLEDGEMENTS}

The authors would like to thank the supported by State Key Lab of Urban Water Resource and Environment (HIT, Grant No. QAK201010)..

\section{REFERENCES}

[1] Carla Reina Costa, Clarice M.R. Botta, Evaldo L.G. Espindola \& Paulo Olivi, Electrochemical treatment of tannery wastewater using DSA electrodes. Journal of Hazardous Materials, 153, pp. 616-627, 2008 .

[2] Wei Ma, Zihong Chen, Zhanxian Gao, Ren Wang, Baodong Wang \& Qi Sun, Study of hydrogen gas production coupled with phenol electrochemical oxidation degradation at different stages. Chemical Engineering Journal, 241, pp. 167-174, 2014.

[3] Runye Zhu, Chunyin Yang, Mingming zhou \& Jiade Wang, Industrial park wastewater deeply treated and reused by a novel electrochemical oxidation reactor. Chemical Engineering Journal, 260, pp. 427-433, 2015.

[4] Lidia Szpyrkowicz, Santosh N. Kaul, Rao N. Neti \& Shanta Satyanarayan, Influence of anode material on electrochemical oxidation for the treatment of tannery wastewater. Water Research, 39, pp. 1601-1613, 2005
[5] C. Ahmed Basha, E. Chithra \& N.K. Sripriyalakshmi, Electrodegradation and biological oxidation of non-biodegradable organic contaminants. Chemical Engineering Journal, 149, pp. 25-34, 2009.

[6] Xinyang Li, Wei Zhu, Chengwen Wang, Liwei Zhang, Yi Qian, Fangqin Xue \& Yue Wu, The electrochemical oxidation of biologically treated citric acid wastewater in a continuous- flow three-dimensional electrode reactor (CTDER). Chemical Engineering Journal, 232, pp. 495-502, 2013.

[7] Xiaoxue Wei, Ziyang Zhang, Qinglan Fan, Xiaoying Yuan \& Dongsheng Guo, The effect of treatment stages on the coking wastewater hazardous compounds and their toxicity. Journal of Hazardous Materials, 239-240, pp. 135-141, 2012.

[8] Haifeng Zhuang, Hongjun Han, Shengyong Jia, Qian Zhao \& Baolin Hou, Advanced treatment of biologically pretreated coal gasification wastewater using a novel anoxic moving bend biofilm reactor (ANMMBR)-biological aerated filter (BAF) system. Bioresource Technology, 157, pp. 223-230, 2014.

[9] Zixing Wang, Xiaochen Xu, Jie Chen \& Fenglin Yang, Treatment of Lurgi coal gasification wastewater in pre-denitrificaiton anaerobic and aerobic biofilm process. Journal of Environmental Chemical Enginerring, 1, pp. 899-905, 2013.

[10] Huiqiang Li, Hongjun Han, Maoan Du \& Wei Wang, Removal of phenols, thiocyanate and ammonium from coal gasification wastewater using moving bed biofilm reactor. Bioresource Technology, 102, pp. 4667-4673, 2011.

[11] Xiuping Zhu, Jinren Ni \& Peng lai, Advanced treatment of biologically pretreated coking wastewater by electrochemical oxidation using boron-droped diamond electrodes. Water Research, 43 ,

pp. 